\title{
Behavioural expressions, imagery and perfectionism
}

Article

Accepted Version

Lee, M., Roberts-Collins, C., Coughtrey, A., Phillips, L. and Shafran, R. (2011) Behavioural expressions, imagery and perfectionism. Behavioural and Cognitive Psychotherapy, 39 (4). pp. 413-425. ISSN 1352-4658 doi:

https://doi.org/10.1017/S1352465810000925 Available at https://centaur.reading.ac.uk/26569/

It is advisable to refer to the publisher's version if you intend to cite from the work. See Guidance on citing.

To link to this article DOI: http://dx.doi.org/10.1017/S1352465810000925

Publisher: Cambridge University Press

All outputs in CentAUR are protected by Intellectual Property Rights law, including copyright law. Copyright and IPR is retained by the creators or other copyright holders. Terms and conditions for use of this material are defined in the End User Agreement.

\section{www.reading.ac.uk/centaur}

\section{CentAUR}

Central Archive at the University of Reading 
Reading's research outputs online 
left running head: $M$. Lee et al.

right running head: Behavioural expressions, imagery and perfectionism

\section{Behavioural Expressions, Imagery and Perfectionism}

Michelle Lee, Cara Roberts-Collins, Anna Coughtrey, Lindsey Phillips and Roz Shafran

University of Reading, $U K$

Reprint requests to Michelle Lee, School of Psychology and Clinical Language Science, University of Reading, Earley Gate, Whiteknights, Reading RG6 6AL, UK. E-mail:

m.j.lee@ reading.ac.uk 
Background: High levels of multidimensional perfectionism may be dysfunctional in their own right and can also impact on the maintenance and treatment of Axis I psychiatric disorders. Aims: This paper sought to describe the behavioural expressions and imagery associated with perfectionism in a non-clinical sample. Method: Participants $(n=59)$ completed a newly developed questionnaire to assess behavioural expressions of perfectionism, and an adapted interview to assess perfectionism-related intrusive mental images. Results: The study found that those high in perfectionism took longer to complete tasks, experienced more checking and safety behaviour whilst carrying out tasks, and had greater trouble actually completing tasks compared to those low in perfectionism. In addition, those with higher levels of perfectionism experienced intrusive mental imagery, which was more distressing, harder to dismiss, and had more impact on behaviour than those with lower levels of perfectionism. Conclusions: This research provides an initial exploration of the specific behaviours and intrusive mental imagery associated with perfectionism. The new behavioural measure of perfectionism could prove useful clinically in the assessment of change; however, these findings are preliminary and warrant replication in a clinical sample in order to examine their treatment implications.

Keywords: Perfectionism, behaviour, mental imagery, assessment

\section{Introduction}

Dysfunctional perfectionism has been suggested to play an important role in the aetiology and maintenance of a number of specific psychological disorders including eating disorders, anxiety, and obsessive-compulsive disorder (Bieling, Summerfeldt, Israeli and Antony, 2004; Hewitt and Flett, 2002; Moretz and McKay, 2009; Wu and Cortesi, 2009), and is the focus of the current research. For example, perfectionism has been found to increase and maintain the 
psychopathology of eating disorders (Bardone-Cone et al., 2007). Not only has research consistently demonstrated a pattern of higher levels of perfectionism amongst individuals with eating disorders (e.g. Halmi et al., 2000; Kaye, Bulik, Thornton, Barbarich and Masters, 2004), it has also been highlighted as a risk factor in the development of an eating disorder (Fairburn, Welch, Doll, Davies and O’Connor, 1997; Fairburn, Cooper, Doll and Welch, 1999; Striegel-Moore et al., 2005), and treatment that includes a focus on the perfectionism itself has recently been found to reduce eating disorder psychopathology (Fairburn et al., 2009; Steele and Wade, 2008). Perfectionism may also have a negative impact on treatment outcome in anorexia nervosa (Sutandar-Pinnock, Woodside, Carter, Olmsted and Kaplan. 2003).

High levels of perfectionism have also been found to be associated with elevated symptoms of anxiety and depression following a distressing event (Flett, Madorsky, Hewitt and Heisel, 2002) and those higher in perfectionism also engage more in rumination about perceived imperfections (Flett, Madorsky, Hewitt and Heisel, 2002). Additionally, it may impede treatment of depression. For example, research has indicated that high levels of dysfunctional perfectionism predict higher depression and greater impaired adjustment at the end of treatment for depression (Blatt, Quinlan, Pilkonis and Shea, 1995), and this may be in part due to the impact of elevated levels of perfectionism on the development of a poor therapeutic alliance (Zuroff et al., 2000).

Within the anxiety disorders, perfectionism plays a particularly important role in cognitive approaches to OCD. For example, the role of perfectionist thinking has been highlighted in specific types of obsessions (doubts about whether a task was completed correctly) and compulsions (washing until it "feels right"; Moretz and McKay, 2009), and the Obsessive Compulsive Cognitions Working Group (1997) view perfectionism as one of six key areas of central importance to OCD. Perfectionism is elevated within this clinical group 
compared to non-clinical controls (e.g. Antony, Purdon, Huta and Swinson, 1998; Sassaroli et al., 2008), and elevated when compared with other anxious samples, including those with generalized anxiety disorder (Bardone-Cone et al., 2007). It has also been suggested that perfectionism may impede the treatment of OCD by impacting on the ability of patients to engage in exposure and response prevention (ERP; Frost, Novara and Rhéaume, 2002).

Despite the importance of dysfunctional perfectionism across mental health problems and an extensive literature on the construct and its measurement (e.g. Shafran and Mansell, 2001), relatively little is known about the phenomenon. In addition, studies that have highlighted the association between perfectionism and psychopathology are not always explicit in terms of the nature of the perfectionism that they assess. For example, a distinction between functional/adaptive perfectionism (i.e. simply striving for high standards in a way that does not cause any difficulties) versus dysfunctional or clinical perfectionism (which is unhelpful or detrimental to one's functioning) is not always made. The aims of the current research were first to examine the behavioural expressions of dysfunctional perfectionism and, second, to examine the nature of intrusive mental imagery associated with dysfunctional perfectionism. The behavioural expressions of perfectionism were of particular interest, considering the importance placed in cognitive-behavioural theories and treatments of psychopathology on the role of such behaviour in the maintenance of psychopathology. Intrusive mental images were also of particular interest given the prominence they play across anxiety disorders, including social phobia and PTSD (Hirsch, Clark, Matthews and Williams 2003; Ehlers, Clark, Hackmann, McManus and Fennell 2005). Indeed, the presence of intrusive thoughts or images is included as one of the diagnostic criteria for both OCD and PTSD. Understanding and modifying such images are becoming important components of cognitive behavioural treatments; for example, in social phobia, updating the negative meanings of self-relevant imagery leads to a reduction in both core negative self-beliefs as 
well as social phobia cognitions (Wild, Hackmann and Clark, 2007, 2008). Given the importance of distorted imagery in psychopathology (in particular, anxiety), the impact of manipulating imagery as a therapeutic tool, and the implications of perfectionism for multiple clinical disorders, it is clearly important to also examine the nature of intrusive mental imagery in perfectionism, both at the clinical and non-clinical level.

In summary, the current study aimed to explore in more detail both the behavioural expressions of perfectionism (using a newly developed assessment tool) and mental imagery associated with high levels of perfectionism (using a revised interview) in a non-clinical sample. The behavioural expressions of perfectionism were explored across five key life domains: house work/maintenance; work; social life; hobbies; and appearance. A standardized self-report questionnaire, the Behavioural Domains Questionnaire (BDQ), was developed for this purpose and the relationship between the severity of perfectionism, its behavioural expressions and other psychopathology was explored. A multidimensional measure of perfectionism, Frost's Multidimensional Perfectionism Scale (MPS-F, Frost, Marten, Lahart and Rosenblate, 1990) was used to assess perfectionism as a non-clinical sample was being assessed. An existing interview-based measure was adapted to explore the nature of mental imagery in people with varying levels of perfectionism.

It was predicted that there would be a relationship between level of perfectionism and behavioural expressions, and between level of perfectionism and perfectionism-related intrusive images, specifically, that those with higher levels of perfectionism would report more perfectionist behaviour (i.e. experience it more frequently) and experience more frequent, more intense, and more distressing intrusive mental imagery, and that such images would have more impact on behaviour, and be harder to dismiss. It was also predicted that these new measures of behaviour and imagery would have greater power in predicting levels 
of general psychopathology than demographic data or general dysfunctional perfectionism scores alone.

\section{Method}

\section{Participants}

The non-clinical sample was recruited via a psychology student research panel $(n=20)$ and poster advertisements $(n=19)$. Posters indicated that research was being conducted into perfectionism, but did not specifically advertise for people with high levels of perfectionism. The sample comprised 49 students and 10 non-students $(78 \%$ female, mean age $=$ 23.71 yrs, $S D=8.31$ ). Participants either received a course credit, or were reimbursed $£ 10$ for their time. Thirteen of the 59 participants had previously consulted a GP for problems relating to anxiety, depression or eating disorders, and 31 considered themselves perfectionists when directly asked "do you consider yourself to be a perfectionist?".

\section{Measures}

The Brief Symptom Inventory (BSI; Derogatis, 1993). This is a 53-item, self-report measure of general psychopathology. It examines problems over the past 4 weeks, rated on a scale of 0 (not at all) to 4 (extremely), with scores ranging from 0-212. It explores 9 primary symptom dimensions with 3 further global severity indices. It takes approximately 10 minutes to complete. The BSI is a reliable and valid measure of symptoms and their intensity at a specific point in time (Derogatis, 1993). It was used in the current study in order to control for general level of psychiatric functioning. Scores of 63 or over are considered to be indicative of clinical severity. 
The Multidimensional Perfectionism Scale (MPS-F; Frost et al., 1990). This is a 35item self-report multidimensional perfectionism questionnaire, with ratings from 1 (strongly disagree) to 5 (strongly agree), with six subscales, each assessing a different aspect of perfectionism. The total score does not include "Organization" as it does not correlate highly with other subscales or total perfectionism. Scores with "Organization" omitted can range from 29-145. It has good overall internal consistency ( $\alpha=0.77$ to 0.93$)$ and good construct validity ( $r=0.42$ to 0.87 ) (Riley, Lee, Cooper, Fairburn and Shafran, 2007). It is a reliable and valid measure of perfectionism and overall scores have significantly correlated with other perfectionism measures (Frost et al., 1990). Rather than the Hewitt and Flett's MPS-H Scale (1988), the MPS-F was used as it looks more at personal rather than general aspects of perfectionism.

The Behavioural Domains Questionnaire (BDQ). This measure was designed by the present authors to assess the behavioural expression of clinical perfectionism across various life domains. It consists of 37 items, with three additional open-ended questions that are not included in the overall score. Items are rated according to frequency of behaviour over the past 4 weeks from 1 (never) to 5 (always). Life domains are as follows: housework (e.g. "how often have you found it difficult to stop cleaning the house because you have been striving to complete it to your personal standards?"), work (e.g. "How often have you checked your work over and over for mistakes?"), social (e.g. "How often have you thought about past social interactions to check to see if your behaviour met your personal standards?"), hobbies (e.g. "How often have you avoided group activities because you wanted to achieve the best and were afraid of being compared"), and appearance (e.g. "How often have you brushed your teeth for longer than 5 minutes?"). There are seven behaviours that are assessed within the questionnaire which were selected after considering which traits in the literature are 
commonly associated with high levels of perfectionism and also by using the clinical experience of those presenting with high levels of perfectionism in a randomized controlled trial (Riley and Shafran, 2005); they are: taking excessive time over tasks; being over thorough; inability to stop a task once started; checking for mistakes; difficulties in task completion; safety behaviour; and avoidance. Each behaviour is scored by summing all relevant items and dividing by the number of items in that category; therefore all behaviours may be scored between 1 and 5 .

The Images Interview (II; adapted from Hackmann, Clark and McManus, 2000). This 48-item, semi-structured interview examines intrusive mental thoughts, images and sensations related to a specific memory. Standardized questions are asked by the experimenter in a fixed order, taking approximately 10-60 minutes depending on the participant. Twelve questions are rated on a scale of $0-10$, with a maximum score of 120 . Forty-three additional questions are open ended, scored as 1 if answered, 0 if not, with a maximum score of 43 . The original schedule (Hackmann et al., 2000) was modified to assess images and early memories linked specifically to perfectionism. Subscales were created by pairing individual questions from the imagery (II-I) and memory (II-M) sections of the interview. Subscales included: Intensity of image ("How intense is this image/memory on a scale from $0-10$ where $0=$ not strong and $10=$ very strong?"); Distress caused by the image (e.g. "How distressing is this image/intrusive thought to you on a scale from $0-10$ where $0=$ not distressing and $10=$ very distressing”); Difficulty in dismissing the image ("How difficult do you find it to get the image out of your head on a scale from $0-10 /$ How difficult to dismiss is the remembered event once you have started thinking about it on a scale from $0-10$ where $0=$ not difficult and $10=$ very difficult"); Impact of imagery on day to day behaviour ("How much does the intrusion of this image affect your day to day activities on a scale from $0-10$ where $0=$ not at all and $10=$ it affects 
them greatly"); and Frequency of imagery (e.g. "How often would you say that you experience this image or related ones on a scale from $0-10$ where $0=$ not often and $10=$ very often"). Each interview was also categorized by its main theme for analysis (see results section). The overall II was found to have excellent internal consistency $(\alpha=0.843)$, confirming it is a valid and reliable measure. Prior to the II, participants were provided with a definition of mental imagery as follows: "Mental images are remembered or invented events you can imagine, that you can picture in your mind's eye, but can also involve smells, sounds and feelings".

\section{$B D Q$ development}

Piloting. The Behavioural Domains Questionnaire (BDQ) was piloted twice to check the comprehensibility of the questions and the scale. Participants involved in this initial piloting phase were sampled opportunistically by experimenters and did not participate in the main study. In the first phase of piloting, 11 participants ( 6 males, 5 females; 2 students, 9 non-students; mean age $34, S D=19.68$ ) answered 39 rated and 4 open questions. Participants were asked to give feedback regarding the clarity and layout of the questionnaire. Following this first phase of piloting, a time frame of "the last 4 weeks" was added. In the second phase of piloting, 10 participants, ( 3 males, 7 females; 4 students, 6 non-students; mean age $=22$, $S D=18.45)$ answered 37 rated and 3 open questions using the new time-frame for answering the questions. Participants gave feedback, and the questionnaire was adjusted to the final state, with 37 rated, and three open questions. Further details about the BDQ are provided in the materials section.

\section{Procedure}


Participants read an information sheet and were asked to sign a consent form if they were willing to participate. They were asked to complete a demographics sheet, and all three questionnaires (BSI, MPS-F, and BDQ). They then completed the Images Interview. Interviews were recorded using a digital audio recorder, but participants were also invited to draw their mental images if that was easier for them. Participants were thanked and debriefed, and provided with contact details in case of further questions. Ethical approval for the study was sought for and granted by the University of Reading's Research Ethics Committee.

\section{Results}

\section{Reliability of the Behavioural Domain Questionnaire}

Cronbach's alpha was calculated to assess the reliability of total BDQ scores as well as specific question groups within the questionnaire. This indicated excellent overall internal consistency $(\alpha=0.918)$ for all 37 items. Four of the seven behaviours had highly reliable internal consistency (spending excessive time on tasks: $\alpha=0.756$; checking: $\alpha=0.737$; difficulties completing tasks: $\alpha=0.732$; avoiding tasks: $\alpha=0.729$ ), while a further two were only slightly less reliable (difficulty stopping a task once started: $\alpha=0.657$; safety behaviours: $\alpha=0.678$ ). Only one behaviour within the questionnaire was not internally consistent - being overly thorough $(\alpha=0.459)$.

\section{Perfectionism and general psychopathology}

MPS-F scores and BSI scores were correlated to assess the relationship between perfectionism and general psychopathology. As expected, there was a highly significant correlation between these two variables $(r=.43, p<.001)$; therefore, in subsequent analyses, the effects of general psychopathology are statistically controlled for using ANCOVAs. 


\section{Behavioural expressions of perfectionism}

Across the whole sample, the most common behavioural expression of perfectionism was safety behaviours $(M=2.73, S D=0.77)$, followed by checking $(M=2.65, S D=0.74)$, trouble completing tasks $(M=2.31, S D=0.95)$, difficulty stopping a task once started $(M=2.25$, $S D=0.88)$, spending excessive time on tasks $(M=2.18, S D=0.74)$, avoiding tasks $(M=1.99$, $S D=0.72)$, and being over thorough $(M=1.58, S D=0.58)$. In terms of domain, perfectionist expressions were greatest for work $(M=2.82, S D=0.95)$, and social areas $(M=2.51, S D=0.61$, followed by hobbies $(M=2.26, S D=0.88)$, appearance $(M=2.02, S D=0.72)$, and housework $(M=2.00, S D=0.77)$.

\section{Comparison of those with high versus low levels of perfectionism}

The sample was split into two groups on the basis of scores on the MPS-F (a median split). Those in the low perfectionism group had a mean MPS-F score of $61.03(S D=11.22)$ and those in the high perfectionism group had a significantly higher mean score of 90.10 $(S D=9.17)(t(57)=10.88, p<.001)$. Demographics of both groups are presented in Table 1. Across the whole sample, $24 \%$ had BSI scores that fell within the clinical range (i.e. were 63 or above). This included 13\% of those with "low" perfectionism scores and $34 \%$ of those with "high" perfectionism scores.

[Tables 1 and 2 near here]

\section{Level of perfectionism and behavioural expressions}

An Independent measures MANOVA was conducted to analyze the effect of perfectionism level on the seven behavioural expressions of the BDQ (spending excessive time, being over thorough, not being able to stop once started, checking, trouble with task completion, safety 
behaviour, and avoidance). The MANOVA was significant $(F(7,51)=7.84, p<.001$, Pillai's Trace $=0.518)$, therefore separate $t$-tests could be conducted. Mean scores across both groups on all BDQ scales are presented in Table 2.

Follow up $t$-tests indicated that those with high MPS-F scores demonstrated more excessive behaviour, found it harder to stop tasks once started, checked their actions more, were more concerned with task completion, and engaged more in safety behaviours than those with low MPS-F scores. Groups did not differ from each other in terms of being overthorough and avoidance. Those with higher MPS-F scores also had significantly higher BSI scores $(57.00$ versus $29.37, t(57)=3.89, p<.001)$. In order to rule out whether elevated BDQ scores were due to these higher BSI scores, analyses were repeated controlling for BSI scores. All group differences remained when BSI scores were controlled.

\section{Level of perfectionism and intrusive mental imagery}

$T$-tests were used to compare image interview scores in those with high and low levels of perfectionism, and mean scores are presented in Table 3. It can be seen that overall scores on the image interview were higher in those with higher levels of perfectionism. This was also true for the images and memory section of the interview individually. In addition, those with higher levels of perfectionism experienced more distress from perfectionism-related imagery, found it harder to dismiss the images, and experienced more negative impact as a result of the imagery. However, they did not differ from those with lower levels of perfectionism in terms of frequency or intensity of imagery.

[Table 3 near here]

Themes of imagery 
Each interview was categorized into one of five themes of the main image, and frequencies of each across the whole sample were as follows: work related $(n=32)$, interpersonal $(n=8)$, creative ( $n=6)$, outdoors-related/sport $(n=9)$ and self-image $(n=4)$. Table 4 provides an example from each of these different theme categories. A Chi-square test was performed to examine if there was an association between level of perfectionism and type of theme presenting. No association was found $\left(\chi^{2}=5.98, d f=5, p=.31\right)$.

[Table 4 near here]

Relationship between behavioural expressions of perfectionism and perfectionism-related imagery

There was a significant positive relationship between scores on the Imagery Interview and total scores on the behavioural domains questionnaire, controlling for BSI scores $(r=.33$, $p=.011$, one-tailed). Specifically, higher imagery scores were significantly associated with higher checking and safety behaviours ( $r=.35$ and .31 respectively) and greater difficulty in completing a task $(r=.28)$, all $p s<.05$.

\section{Ability of the $B D Q$ and Imagery Interview to predict general psychopathology}

In order to further explore the association of the newly developed behavioural domains questionnaire and the revised imagery interview with general psychopathology (BSI scores), hierarchical linear multiple regression analyses were conducted with BSI scores as the dependent variable. In a first step, age and gender were entered to control for demographic factors. Scores on the MPS-F were entered in a second step, and scores on the Behavioural Domains Questionnaire and Imagery Interview were entered into the regression equation in a third step in order to determine the amount of variance in general psychopathology that could be uniquely explained by these new measures, independently of demographics and level of 
perfectionism. Results are presented in Table 5. Tolerance statistics for analyses were acceptable. Age and gender accounted for less than $1 \%$ of the variance in BSI scores $(F(2,56)$ $=0.25, p=.78$ ). Adding MPS-F scores to the equation accounted for a further $14 \%$ of the variance $(F(3,55)=4.12, p=.01)$, and adding BDQ scores and Imagery Interview scores accounted for a further $29 \%$ of the variance in $\operatorname{BSI} \operatorname{scores}(F(5,53)=5.73, p<.001)$. It can be seen from Table 5 that this additional variance was best accounted for by the DBQ rather than the Imagery Interview.

[Table 5 near here]

\section{Discussion}

The first aim of this study was to explore the behavioural expression of perfectionism in a non-clinical sample, using a new assessment tool. The measure designed for this purpose had excellent overall internal consistency and indicated that individuals with higher levels of perfectionism reported behaviours that took more time, were harder to stop, had more problems completing tasks, and engaged more in checking and safety behaviours. This is consistent with and extends previous research indicating that people with dysfunctional perfectionism take longer to complete tasks, doubt their decisions, and report more negative consequences of their behaviours (Rhéaume et al., 2000). The results from this study support our clinical observation that the behavioural expressions of perfectionism are prominent and warrant inclusion in any cognitive behavioural analysis.

However, contrary to prediction, those with higher levels of perfectionism do not show more avoidance behaviours, and are not more overly-thorough. This may suggest that in a non-clinical sample at least, "over thorough" behaviours could also come from being conscientious, a normal behaviour that has been correlated with healthy perfectionism (Stumpf and Parker, 2000), and that "avoidance" can be both functional and dysfunctional 
(Hamachek, 1978). It would be important in future research to examine this issue in a clinical sample. It may, on the other hand, be that these behaviours are simply not associated with dysfunctional perfectionism. This should be investigated in future work and, if this is the case, these items should be removed from the BDQ.

The current research also investigated the phenomenology of intrusive mental imagery in multidimensional perfectionism. This study found that those with higher levels of perfectionism experienced more distress as a result of this intrusive mental imagery, found it harder to dismiss the imagery, and experienced more negative impact as compared with those with lower levels of perfectionism. This is consistent with the view that perfectionism is "a form of psychopathology maintained by specific cognitions and behaviour” (Riley et al., 2007, p. 229) and these findings present evidence explicitly associating perfectionism with mental imagery. The finding that those with higher levels of perfectionism experience mental images with more adverse consequences than those low in perfectionism should inform any cognitive-behavioural account and treatment of perfectionism. Those higher in perfectionism demonstrated cognitive disruption, in the form of intrusive images, and these findings may be important for those with pathological forms of perfectionism (Shafran, Cooper and Fairburn, 2002). These findings warrant replication in a clinical sample in order to examine the treatment implications. Future research may also wish to specifically examine behavioural expressions and intrusive imagery associated with clinical perfectionism (Shafran et al., 2002). If the findings are replicated, it implies that, as the images associated with perfectionism appear to be distressing and difficult to dismiss, part of the CBT protocol to address perfectionism could effectively include imagery restructuring techniques.

This study also found that general psychopathology was significantly higher in those with higher perfectionism scores, and a greater percentage of those with higher levels of perfectionism had seen their GP for problems relating to anxiety and/or depression. However, 
the association noted between the MPS-F and the BDQ was not simply a function of increased psychopathology as it remained when BSI scores were statistically controlled for. It may be that the behaviour associated with perfectionism is causing significant distress for some people, and may be contributing to difficulties with mood and anxiety. Indeed, the behavioural expressions of perfectionism as measured by the BDQ were able to predict general levels of psychopathology over and above demographic variables and MPS-F scores.

In conclusion, this research provides an initial exploration of the intrusive mental images and specific behaviours associated with perfectionism. The results offer scope for fleshing out the details of the cognitive-behavioural model of perfectionism, as both mental imagery and intrusive thoughts were found to be closely associated with the stringent pursuit of personally demanding standards. The new behavioural measure of perfectionism could prove useful clinically in the assessment of perfectionism, and an adaption of the existing Imagery Interview might also have clinical utility However, it should be noted that this research was largely exploratory in nature, and replicating findings in a clinical population are essential in order to determine their reliability, and to shed further light on clinically relevant perfectionist behaviours and mental images.

\section{Acknowledgements}

The authors would like to thank staff from the Charlie Waller Institute and the University of Reading for their support in this research. The authors would also like to give thanks to all the participants who took part and an anonymous reviewer for helpful comments on an earlier version of this manuscript.

\section{References}


Antony, M. M., Purdon, C. L., Huta, V. and Swinson, R. P. (1998). Dimensions of perfectionism across the anxiety disorders. Behaviour Research and Therapy, 36, $1143-1154$.

Bardone-Cone, A. M., Wonderlich, S. A., Frost, R. O., Bulik, C. M., Mitchell, J. E., Uppala, S. and Simonich, H. (2007) Perfectionism and eating disorders: current status and future directions. Clinical Psychology Review, 27, 384-405.

Bieling, P. J., Summerfeldt, L.J., Israeli, A. L. and Antony, M. A. (2004). Perfectionism as an explanatory construct in the co-morbidity of Axis 1 disorders. Journal of Psychopathology and Behaviour Assessment, 26, 193-201.

Bizuel, C., Sadowsky, N. and Riguad, D. (2001). The prognostic value of EDI scores in anorexia nervosa patients: a prospective follow-up study of 5-10 years. European Psychiatry, 16, 232-238.

Blatt, S. J., Quinlan, D. M., Pilkonis, P. A. and Shea, M. T. (1995). Impact of perfectionism and need for approval on the brief treatment of depression: the National Institute of Mental Health Treatment of Depression Collaborative Research Program revisited. Journal of Consulting and Clinical Psychology, 63, 125-32.

Derogatis, L. R. (1993). BSI Brief Symptom Inventory: administration, scoring, and procedures manual (4th Ed.). Minneapolis, MN: National Computer Systems.

Ehlers, A., Clark, D.M., Hackmann, A., McManus, F. and Fennell, M. (2005). Cognitive therapy for PTSD: development and evaluation. Behaviour Research and Therapy, 43, 413-431.

Fairburn, C.G., Cooper, Z., Doll, H. A., O’Connor, M. E., Bohn, K., Hawker, D. M., Wales, J. A. and Palmer, R. L. (2009). Transdiagnostic cognitive behavioral therapy for patients with eating disorders: a two-site trial with 60-week follow-up. American Journal of Psychiatry, 166, 311-319. 
Fairburn, C. G., Cooper, Z., Doll, H. A. and Welch, S. L. (1999). Risk factors for anorexia nervosa: three integrated case-control comparisons. Archives of General Psychiatry, 56, 468-476.

Fairburn, C. G., Welch, S. L., Doll, H. A., Davies, B. A. and O'Connor, M. E. (1997). Risk factors for bulimia nervosa: a community-based case-control study. Archives of General Psychiatry, 54, 509-517.

Flett, G. L., and Hewitt, P. L. (Eds.) (2002). Perfectionism. Theory, Research and Treatment. American Psychological Association: Washington, DC

Flett, G. L., Madorsky, D., Hewitt, P. L. and Heisel, M. J. (2002). Perfectionism cognitions, rumination, and psychological distress. Journal of Rational-Emotive and Cognitive-Behavior Therapy, 20, 31-45.

Frost, R. O., Marten, P., Lahart, C. and Rosenblate, R. (1990). The dimensions of perfectionism. Cognitive Therapy and Research, 14, 449-468.

Frost, R. O., Novara, K. and Rhéaume, J. (2002). Perfectionism in obsessive compulsive disorder. In R O. Frost and G. Steketee (Eds.), Cognitive Approaches to Obsessions and Compulsions: theory, assessment, and treatment (pp. 91-106). Amsterdam: Pergamon Press.

Hackmann A; Clark D M; McManus F. (2000). Recurrent images and early memories in social phobia. Behaviour research and Therapy, 38, 601-10.

Halmi, K. A., Sunday, S. R., Strober, M., Kaplan, A., Woodside, D. B., Fichter, M., Treasure, J., Berrettini, W. H. and Kaye, W. H. (2000). Perfectionism in anorexia 
nervosa: variation by clinical subtype, obsessionality, and pathological eating behavior. American Journal of Psychiatry, 157, 1799-1805.

Hamachek, D. E. (1978). Psychodynamics of normal and neurotic perfectionism. Psychology: A Journal of Human Behaviour, 15, 27-33.

Hewitt, P. L., and Flett, G. L. (1988). MPS. Unpublished manuscript. York University, Ontario, Canada.

Hirsch, C. R., Clark, D. M., Mathews, A. and Williams, R. (2003). Self-images play a causal role in social phobia. Behaviour Research and Therapy, 41, 909-921.

Kaye, W. H., Bulik, C. M., Thornton, L., Barbarich, N. and Masters, K. (2004). Comorbidity of anxiety disorders with anorexia and bulimia nervosa. American Journal of Psychiatry, 161, 2215-2221.

Moretz, M. W. and McKay, D. (2009). The role of perfectionism in obsessive-compulsive symptoms: "not just right" experiences and checking compulsions. Journal of Anxiety Disorders, 23, 640-644.

Obsessive Compulsive Working Group (1997). Cognitive assessment of obsessivecompulsive disorder. Behaviour Research and Therapy, 35, 667-681.

Rhéaume, J., Freeston, M. H., Ladouceur, R., Bouchard, C., Gallant, L., Talbot, F., et al. (2000). Functional and dysfunctional perfectionists: are they different on compulsivelike behaviors? Behaviour Research and Therapy, 38, 119-129.

Riley, C. and Shafran, R. (2005). Clinical perfectionism: a preliminary qualitative analysis. Behavioural and Cognitive Psychotherapy, 33, 369-374. 
Riley, C., Lee, M, Cooper, Z., Fairburn, C. G. and Shafran, R. (2007). A randomized controlled trial of cognitive-behaviour therapy for clinical perfectionism: a preliminary study. Behaviour Research and Therapy, 45, 2221-2231.

Sassaroli, S., Lauro, L. J. R., Ruggiero, G. M., Mauri, M. C., Vinai, P. and Frost, R. (2008). Perfectionism in depression, obsessive compulsive disorder and eating disorders. Behaviour Research and Therapy, 46, 757-765.

Shafran, R., Cooper, Z. and Fairburn, C. G. (2002). Clinical perfectionism: a cognitive behavioural analysis. Behaviour Research and Therapy, 40, 773-791.

Shafran, R. and Mansell, W. (2001). Perfectionism and psychopathology: a review of research and treatment. Clinical Psychology Review, 21, 879-906.

Steele, A. L. and Wade, T. D. (2008). A randomized trial investigating guided self-help to reduce perfectionism and its impact on bulimia nervosa. Behaviour Research and Therapy, 46, 1316-1323.

Striegel-Moore, R. H, Fairburn, C. G., Wilfley, D. E., Pike, K. M., Dohm, F.A. and Kraemer, H.C. (2005). Toward an understanding of risk factors for binge eating disorder in black and white women: a community-based case-control study. Psychological Medicine, 35, 147-156.

Stumpf, H. and Parker, W. D. (2000). A hierarchical structural analysis of perfectionism and its relation to other personality characteristics. Personality and Individual Differences, 28, 837-852.

Sutandar-Pinnock, K., Woodside, D.B., Carter, J.C., Olmsted, M.P. and Kaplan, A.S. (2003). Perfectionism in anorexia nervosa: a 6-24 month follow-up study. International Journal of Eating Disorders, 33, 225-229.

Wild, J., Hackmann, A. and Clark, D. M. (2007). When the present visits the past: updating 
traumatic memories in social phobia. Journal of Behaviour Therapy and Experimental Psychology, 38, 386-401.

Wild, J., Hackmann, A. and Clark, D. M. (2008). Rescripting early memories linked to negative images in social phobia: a pilot study. Behavior Therapy, 39, 47-56.

Wu, K. D. and Cortesi, G. T. (2009). Relations between perfectionism and obsessivecompulsive symptoms: examination of specificity among the dimensions. Journal of Anxiety Disorders, 23, 393-400.

Zuroff, D. C., Blatt, S. J., Sotsky, S. M., Krupnick, J. L., Marrtin, D. J., Sanislow, C. A. and Simmens, S. A. ( 2000). Relationship between therapeutic alliance and perfectionism to outcome in brief outpatient treatment of depression. Journal of Consulting and Clinical Psychology, 68, 114-124. 
Table 1. Comparison of those with high and low scores on the MPS-F on demographic variables and general psychopathology

\begin{tabular}{llll}
\hline Measure & $\begin{array}{l}\text { Low MPS-F score } \\
(n=30)\end{array}$ & $\begin{array}{l}\text { High MPS-F score } \\
(n=29)\end{array}$ & $\begin{array}{l}\text { Entire sample } \\
(n=59)\end{array}$ \\
\hline $\begin{array}{l}\text { Age }(S D) \\
\text { Gender }\end{array}$ & $\begin{array}{l}26.23(10.81) \\
\text { Occupation }\end{array}$ & $\begin{array}{l}21.10(2.84) \\
93 \% \text { female }\end{array}$ & $\begin{array}{l}23.71(8.31) \\
\text { Contact with GP for }\end{array}$ \\
$\begin{array}{l}\text { (30\% students } \\
\text { anxiety/depression }\end{array}$ & $\begin{array}{l}86 \% \text { students } \\
\text { Consider themselves to be }\end{array}$ & $31 \%$ Yes & $78 \%$ female \\
perfectionist & $30 \%$ Yes & $72 \%$ Yes & $22 \%$ Yes \\
BSI score $(S D)$ & & & $51 \%$ Yes \\
& $29.37(20.97)$ & $57.00(32.52)$ & $42.95(30.41)$ \\
\end{tabular}


Table 2. Comparison of those with high and low levels of perfectionism on BDQ scales (MPS-F median split)

\begin{tabular}{llllll}
\hline BDQ subscale & \multicolumn{2}{l}{ Low MPS-F scores } & \multicolumn{2}{l}{ High MPS-F scores } & $t, p$ \\
& $M$ & $S D$ & $M$ & $S D$ & \\
\hline Excessive time & 1.89 & 0.50 & 2.48 & 0.83 & $t(57)=3.33, p=.002$ \\
Over thorough & 1.50 & 0.53 & 1.67 & 0.67 & $t(57)=1.14, p=.26, \mathrm{~ns}$ \\
Can't stop & 1.80 & 0.62 & 2.71 & 0.88 & $t(57)=4.59, p<.001$ \\
Checking & 2.24 & 0.57 & 3.07 & 0.64 & $t(57)=5.32, p<.001$ \\
Task completion & 1.73 & 0.69 & 2.92 & 0.79 & $t(57)=6.21, p<.001$ \\
Safety behaviour & 2.31 & 0.69 & 3.15 & 0.62 & $t(57)=4.92, p<.001$ \\
Avoidance & 1.90 & 0.64 & 2.09 & 0.78 & $t(57)=1.03, p=.31, \mathrm{~ns}$ \\
\hline
\end{tabular}


Table 3. Means and standard deviations from the Image Interview for those with high and low levels of perfectionism (MPS-F median split)

\begin{tabular}{|c|c|c|c|c|c|}
\hline \multirow[t]{2}{*}{ Measure } & \multicolumn{2}{|c|}{ Low MPS-F } & \multicolumn{2}{|c|}{ High MPS-F } & \multirow[t]{2}{*}{$t, p$} \\
\hline & $M$ & $S D$ & $M$ & $S D$ & \\
\hline $\begin{array}{l}\text { Image interview: } \\
\text { total score }\end{array}$ & 52.10 & 21.76 & 72.72 & 13.27 & $t(57)=4.38, p<.001$ \\
\hline $\begin{array}{l}\text { Image interview: } \\
\text { Memories }\end{array}$ & 17.47 & 11.57 & 25.31 & 7.58 & $t(57)=3.07, p=.003$ \\
\hline $\begin{array}{l}\text { Image interview: } \\
\text { Images }\end{array}$ & 17.97 & 7.22 & 26.52 & 5.46 & $t(57)=5.12, p<.001$ \\
\hline Intensity of image & 5.97 & 2.27 & 6.45 & 2.18 & $t(57)=0.83, p=.41, \mathrm{~ns}$ \\
\hline $\begin{array}{l}\text { Distress caused by } \\
\text { image }\end{array}$ & 2.67 & 2.66 & 5.58 & 2.29 & $t(57)=4.51, p<.001$ \\
\hline $\begin{array}{l}\text { Difficulty in } \\
\text { dismissing image }\end{array}$ & 3.87 & 2.78 & 6.55 & 2.59 & $t(57)=3.84, p<.001$ \\
\hline Impact of image & 3.30 & 2.90 & 5.76 & 2.29 & $t(57)=3.60, p=.001$ \\
\hline Frequency of image & 5.33 & 2.66 & 6.41 & 2.40 & $t(57)=1.64, p=.11, \mathrm{~ns}$ \\
\hline
\end{tabular}


Table 4. Examples of images discussed

\begin{tabular}{|c|c|}
\hline Theme & Example \\
\hline Work/academia-related & $\begin{array}{l}\text { One participant reported an image of her classroom when she } \\
\text { was } 16 \text { and just starting her GCSEs - she would see a medley of } \\
\text { teachers' faces all merging together saying how hard the work } \\
\text { would be. She reported actually smelling the school, feeling } \\
\text { heaviness in her arms and legs and feeling like something was } \\
\text { pressing down on her head. }\end{array}$ \\
\hline Interpersonal & $\begin{array}{l}\text { One participant, when talking about how she strived for a good } \\
\text { relationship with her father, spoke about a frequent image that } \\
\text { would come to mind of his face being "quite mean" and having a } \\
\text { "disgusted" look on his face because of how stupid he thought she } \\
\text { was. }\end{array}$ \\
\hline Self-image & $\begin{array}{l}\text { One participant reported getting images of herself as being } \\
\text { thinner than she really was, or imagining things that she had eaten } \\
\text { that she shouldn't have, in an incentive to lose weight. }\end{array}$ \\
\hline Creative & $\begin{array}{l}\text { One participant reported experiencing mental imagery of a } \\
\text { specific sound to a tune that would be played over and over in his } \\
\text { mind when working on a musical composition. Playing the sound } \\
\text { over and over again whilst working would help him create } \\
\text { something of high quality. }\end{array}$ \\
\hline Outdoors/Sport & $\begin{array}{l}\text { One participant, when training would have his goal in his mind. } \\
\text { He reported enjoying the tightness in his chest and breathing } \\
\text { more deeply and having a feeling of being "cleaner" when he had } \\
\text { worked harder. He said that he often felt like a gym freak, but } \\
\text { "you can't help it, you just have to keep doing it". }\end{array}$ \\
\hline
\end{tabular}


Table 5. Predictors of Brief Symptom Inventory scores (BSI) in the linear regression models

\begin{tabular}{|c|c|c|c|c|c|c|}
\hline & $B$ & $S E B$ & $\beta$ & $t$ & $p$ & $\begin{array}{c}\text { Partial } \\
r\end{array}$ \\
\hline \multicolumn{7}{|l|}{ Step 1} \\
\hline Constant & 33.91 & 27.27 & & & & \\
\hline Age & -.08 & .54 & -.02 & .14 & .89 & .02 \\
\hline Gender & 6.10 & 10.67 & .08 & .57 & .57 & .08 \\
\hline \multicolumn{7}{|l|}{ Step 2} \\
\hline Constant & -14.31 & 28.62 & & & & \\
\hline Age & .13 & .50 & .04 & .27 & .79 & .04 \\
\hline Gender & -1.32 & 10.00 & .02 & .13 & .90 & .02 \\
\hline MPS-F & .749 & .22 & .44 & 3.43 & .001 & .43 \\
\hline \multicolumn{7}{|l|}{ Step 3} \\
\hline Constant & -35.56 & 28.39 & & & & \\
\hline Age & .23 & .48 & .06 & .48 & .63 & .06 \\
\hline Gender & -.90 & 9.12 & -.01 & -.10 & .92 & -.01 \\
\hline MPS-F & .14 & .27 & .08 & .53 & .60 & .07 \\
\hline BDQ & .74 & .20 & .54 & 3.64 & .001 & .45 \\
\hline Image Interview & .06 & .54 & .02 & .11 & .91 & .01 \\
\hline
\end{tabular}

